\title{
HERMITE-HADAMARD TYPE INEQUALITY FOR CERTAIN SCHUR CONVEX FUNCTIONS
}

\author{
PÁl Burai, Judit MaKó AND PATRICIA SzOKOL
}

Abstract. The main goal of this paper is to prove a Hermite-Hadamard type inequality for certain Schur convex functions using, as one of the main tools in the proof, a Korovkin-type approximation theorem.

Mathematics subject classification (2010): 26B25, 41A36, 26D15, $39 \mathrm{~B} 62$.

Keywords and phrases: Hermite-Hadamard inequality, Korovkin theorem, positive linear functional, convexity, circulant matrices, doubly stochastic matrices.

\section{REFERENCES}

[1] Francesco Altomare And Michele Campiti, Korovkin-type approximation theory and its applications, volume 17 of De Gruyter Studies in Mathematics, Walter de Gruyter \& Co., Berlin, 1994.

[2] A. Azócar, J. Giménez, K. Nikodem, And J. L. SÁncheZ, On strongly midconvex functions, Opuscula Math. 31, 1, 2011, 15-26.

[3] F. A. BEHRINGER, On Karamardian's theorem about lower semicontinuous strictly quasiconvex functions, Z. Oper. Res. Ser. A-B 23, 1, 1979, A17-A48.

[4] Mihály Bessenyei, The Hermite-Hadamard inequality on simplices, Amer. Math. Monthly 115, 4, 2008, 339-34.

[5] MihÁly BeSSENYEI, Hermite-Hadamard-type inequalities for generalized convex functions, JIPAM. J. Inequal. Pure Appl. Math. 9, 3, 2008, Article 63.

[6] Mihály Bessenyei ANd Zsolt PÁLES, Hadamard-type inequalities for generalized convex functions, Math. Inequal. Appl. 6, 3, 2003, 379-392.

[7] Mihály Bessenyei AND Zsolt PÁles, Characterization of convexity via Hadamard's inequality, Math. Inequal. Appl. 9, 1, 2006, 53-62.

[8] Harald Bohman, On approximation of continuous and of analytic functions, Ark. Mat. 2, 1, 1952 , 43-56.

[9] PÁL BURAI, Monotone operators and local-global minimum property of nonlinear optimization problems, Ann. Univ. Sci. Budapest. Sect. Comput. 40, 1, 2013, 151-158.

[10] PÁL BURAI, Local-global minimum property in unconstrained minimization problems, J. Optim. Theory Appl. 162, 1, 2014, 36-46.

[11] PÁl Burai And Judit Makó, On certain Schur-convex functions, Publ. Math. Debrecen 89, 3, 2016, 307-319.

[12] Philip J. Davis, Circulant matrices, John Wiley \& Sons, A Wiley-Interscience Publication, Pure and Applied Mathematics, New York-Chichester-Brisbane, 1979.

[13] S. S. Dragomir And R. P. AgARwal, Two inequalities for differentiable mappings and applications to special means of real numbers and to trapezoidal formula, Appl. Math. Lett. 11, 5, 1998, 91-95.

[14] Richard S. Ellis, Volume of an N-simplex by multiple integration, Elem. Math. 31, 3, 1976, 57-59.

[15] Attila Gilányi, KaZimierz Nikodem, and Zsolt PÁles, Bernstein-Doetsch type results for quasiconvex functions, Math. Inequal. Appl. 7, 2, 2004, 169-175.

[16] J. HADAMARD, Étude sur les propriétés des fonctions entières et en particulier d'une fonction considérée par Riemann, J.Math. Pures Appl. 58, 1, 1893, 171-215.

[17] VILMOS KOMORNIK, Lectures on functional analysis and the Lebesgue integral, Translated from the 2002 French original, Universitext. Springer-Verlag, London, 2016. 
[18] P. P. KorovkIn, On convergence of linear positive operators in the space of continuous functions, Doklady Akad. Nauk SSSR (N.S.) 90, 1, 1953, 961-964.

[19] P. P. KorovKIn, On convergence of linear positive operators in the space of continuous functions, Translated from the Russian ed. (1959). Russian Monographs and Texts on Advanced Mathematics and Physics, Vol. III, Gordon and Breach Publishers, Inc., New York; Hindustan Publishing Corp. (India), Delhi, 1960.

[20] M. KUCZMA, An introduction to the theory of functional equations and inequalities, Birkhäuser Verlag, Basel, second edition, Cauchy's equation and Jensen's inequality, Edited and with a preface by Attila Gilányi, New York; Hindustan Publishing Corp. (India), Delhi, 2009.

[21] Judit Makó AND ATtila Ház, On approximate Hermite-Hadamard type inequalities, J. Convex Anal. 24, 2, 2017, 349-363.

[22] Judit MaKó AND Zsolt PÁLes, Korovkin type theorems and approximate Hermite-Hadamard inequalities, J. Approx. Theory 164, 8, 2012, 1111-1142.

[23] CONSTANTIN P. NicUlesCu, The Hermite-Hadamard inequality for log-convex functions, Nonlinear Anal 75, 2, 2012, 662-669.

[24] Constantin P. Niculescu and Lars-Erik Persson, Old and new on the Hermite-Hadamard inequality, Real Anal. Exchange 29, 2, 2003/04, 663-685.

[25] KAZIMierZ Nikodem AND MateusZ Nikodem, Remarks on $t$-quasiconvex functions, Math. Inequal. Appl. 12, 4, 2009, 711-717.

[26] KAZIMIERZ Nikodem AND Zsolt PÁLES, Characterizations of inner product spaces by strongly convex functions, Banach J. Math. Anal. 5, 1, 2011, 83-87.

[27] B. T. POLJAK, Existence theorems and convergence of minimizing sequences for extremal problems with constraints, Dokl. Akad. Nauk SSSR 166, 1, 1966, 287-290.

[28] G. E. SOBCZYK, Simplicial calculus with geometric algebra, In Clifford algebras and their applications in mathematical physics (Montpellier, 1989), volume 47 of Fund. Theories Phys., pages 279-292, Kluwer Acad. Publ., Dordrecht, 1992.

[29] Kuei-Lin Tseng, Shiow Ru Hwang, and S. S. Dragomir, On some new inequalities of Hermite-Hadamard-Fejér type involving convex functions, Demonstratio Math. 40, 1, 2007, 51-64. 